\title{
Characterization of neuraminidase inhibitor-resistant influenza virus isolates from immunocompromised patients in the Republic of Korea
}

Heui Man Kim, Namjoo Lee, Mi-Seon Kim, Chun Kang and Yoon-Seok Chung ${ }^{*}$ (D)

\begin{abstract}
Background: The emergence of influenza viruses resistant to anti-influenza drugs is a threat to global public health. The Korea Centers for Disease Control and Prevention operates the Korea Influenza and Respiratory Viruses Surveillance System (KINRESS) to monitor epidemics of influenza and Severe Acute Respiratory Infection (SARI) to identify mutated influenza viruses affecting drug resistance, pathogenesis, and transmission.

Methods: Oropharyngeal swab samples were collected from KINRESS and SARI during the 2018-2019 season. The specimens confirmed influenza virus using real-time RT-PCR on inoculated MDCK cells. HA and NA sequences of the influenza viruses were analyzed for phylogeny and mutations. Neuraminidase inhibition and hemagglutination inhibition assays were utilized to characterize the isolates.

Results: Two A(H1N1)pdm09 isolates harboring an H275Y substitution in the neuraminidase sequence were detected in patients with acute hematologic cancer. They had prolonged respiratory symptoms, with the virus present in the respiratory tract despite oseltamivir and peramivir treatment. Through the neuraminidase inhibition assay, both viruses were found to be resistant to oseltamivir and peramivir, but not to zanamivir. Although hemagglutinin and neuraminidase phylogenetic analyses suggested that the $2 \mathrm{~A}(\mathrm{H} 1 \mathrm{~N} 1) \mathrm{pdm} 09$ isolates were not identical, their antigenicity was similar to that of the 2018-19 influenza vaccine virus.

Conclusions: Our data indicate the utility of monitoring influenza-infected immunocompromised patients in general hospitals for the early detection of emerging neuraminidase inhibitor-resistant viruses and maintaining continuous laboratory surveillance of patients with influenza-like illness in sentinel clinics to monitor the spread of such new variants. Finally, characterization of the virus can inform the risk assessment for future epidemics and pandemics caused by drug-resistant influenza viruses.
\end{abstract}

Keywords: Influenza virus, Drug resistance, H275Y, Immunocompromised patients

\footnotetext{
* Correspondence: rollstone93@korea.kr

Division of Viral Diseases, Center for Laboratory Control of Infectious Diseases, Korea Centers for Disease Control and Prevention, Cheongju-si, South Korea
}

C C The Author(s). 2020 Open Access This article is licensed under a Creative Commons Attribution 4.0 International License, which permits use, sharing, adaptation, distribution and reproduction in any medium or format, as long as you give appropriate credit to the original author(s) and the source, provide a link to the Creative Commons licence, and indicate if changes were made. The images or other third party material in this article are included in the article's Creative Commons licence, unless indicated otherwise in a credit line to the material. If material is not included in the article's Creative Commons licence and your intended use is not permitted by statutory regulation or exceeds the permitted use, you will need to obtain permission directly from the copyright holder. To view a copy of this licence, visit http://creativecommons.org/licenses/by/4.0/. The Creative Commons Public Domain Dedication waiver (http://creativecommons.org/publicdomain/zero/1.0/) applies to the data made available in this article, unless otherwise stated in a credit line to the data. 


\section{Background}

Neuraminidase inhibitors (NAIs) are globally utilized for the treatment and prevention of influenza types $\mathrm{A}$ and $\mathrm{B}$ infection [1], which are stockpiled by some countries, including the Republic of Korea, against unexpected pandemics. NAIs suppress the action of neuraminidase (NA) on the surface of the virus to prevent the spread of progeny virus from infected cells [2]. Oseltamivir and peramivir, the most commonly used drugs for patients with influenza-like illnesses in the Republic of Korea, help to relieve clinical symptoms within 2 days of symptom manifestation and shorten the virus-release period in the respiratory tract [1]. Baloxavir, a cap-dependent endonuclease inhibitor, was also recently licensed in the United States, following Japan [3]. However, since most recently detected type A influenza viruses harbor the resistance variation $\mathrm{S} 31 \mathrm{~N}$ in the matrix gene, the M2 proton-channel blockers amantadine and rimantadine are no longer clinically applied [4].

The Korea Centers for Diseases Control and Prevention (KCDC) has operated the Korea Influenza and Respiratory Viruses Surveillance System (KINRESS) to monitor epidemic features of influenza viruses and analyze virus characteristics, including drug resistance, since 2000. The KCDC carries out diagnostic testing for influenza viruses in respiratory specimens requested by general hospitals as a national standard laboratory. If a drug resistance mutation is found in the NA gene, the KINRESS attempts to isolate the virus and perform phenotypic analysis (NA inhibition assay). The typical drug-resistance substitutions in NA include H275Y, E119D/G, and Q136R for A(H1N1)pdm09; E119V, D151G/V/D, R224K, E276D, R292K, and N294S for A (H3N2); and G104E, E117A/D, H134Y, and R150K for B virus [5], although additional single and combination mutations may also result in NAI drug resistance (World Health Organization (WHO)) [6]. Flusurver provides genetic analysis tools for screening drug-resistance and variant mutations to facilitate genetic characterization of viruses [7]. Fluorescence-based NA inhibition assays using the MUNANA substrate have been conducted to confirm drug-resistant virus phenotyping [8]. NAI-resistant viruses were identified in cases in which influenza virus was continuously detected following NAI treatment of hospitalized, immunosuppressed patients, rather than in clinical outpatients [9]. Here, drug-resistant $\mathrm{A}(\mathrm{H} 1 \mathrm{~N} 1) \mathrm{pdm} 09$ viruses were detected via the KINRESS in patients with acute hematologic cancer not exhibiting recovery despite oseltamivir and peramivir administration; these were characterized genetically and antigenically following isolation.

\section{Methods}

Clinical specimen collection

Oropharyngeal swab samples were collected from patients with influenza-like illness through the KINRESS and processed in the national standard laboratory. Swabs were stored in Viral Transport Media (BD, San Jose, CA, USA) until further analysis.

\section{Viral RNA extraction}

Viral RNA was extracted from $140 \mu \mathrm{L}$ of sample medium using the QIAamp Viral RNA Mini Kit (Qiagen, Hilden, Germany), according to the manufacturer's instructions.

Table 1 Primer and probe sequence information to detect influenza virus type (A/B) and subtype $(H 1 / H 3)$

\begin{tabular}{|c|c|c|c|}
\hline Type/Subtype & Primer/probe & Sequence $\left(5^{\prime}-3^{\prime}\right)$ & Target (bp) \\
\hline \multirow[t]{3}{*}{$\bar{A}$} & Forward & AATCCTGTCACCTCTGACTAAGG & \multirow{3}{*}{$\begin{array}{l}\text { Matrix } \\
(98)\end{array}$} \\
\hline & Reverse & CATTYTGGACAAAKCGTCTACG & \\
\hline & Probe & FAM-TGCAGTCCTCGCTCAC-MGBNFQ & \\
\hline \multirow[t]{3}{*}{ B } & Forward & GAATGCTGTCAATGAATATTGAGGG & \multirow{3}{*}{$\begin{array}{l}\text { Nucleoprotein } \\
\text { (77) }\end{array}$} \\
\hline & Reverse & CATTGAGTCATTCATCATCTTGAGTAGAT & \\
\hline & Probe & VIC-TCCTITGACATCTGCAT-MGBNFQ & \\
\hline \multirow[t]{3}{*}{$\mathrm{H} 1$} & Forward & AACAATTCAACAGACACTGTAGACACAGT & \multirow[t]{3}{*}{ Hemagglutinin (144) } \\
\hline & Reverse & GGGCTACCCCTCTTAGTTTRCATAGTT & \\
\hline & Probe & FAM- ATGTAACAGTAACACACTCTGT-MGBNFQ & \\
\hline \multirow[t]{3}{*}{$\mathrm{H} 3$} & Forward & GGAATGGTTTGTCATTGGGAAT & \multirow[t]{3}{*}{ Hemagglutinin (95) } \\
\hline & Reverse & AAGCTCAATAATGAGRTCAGATGCA & \\
\hline & Probe & VIC-CTTCCATTTGGAGTRATRCA-MGBNFQ & \\
\hline \multirow[t]{3}{*}{ IPC } & Forward & AGATTTGGACCTGCGAGCG & \multirow{3}{*}{$\begin{array}{l}\text { GAPDH } \\
(65)\end{array}$} \\
\hline & Reverse & GAGCGGCTGTCTCCACAAGT & \\
\hline & Probe & Cy5-TTCTGACCTGAAGGCTCTGCGCG-BHQ & \\
\hline
\end{tabular}


Table 2 Sequencing primers for HA and NA of A(H1N1)pdm09 virus

\begin{tabular}{llll}
\hline Primers (F/R) & Gene (subtype) & Locus & Sequence $\left(5^{\prime}-3^{\prime}\right)$ \\
\hline A-uni-HA-1F & HA & $1-28$ & TATTCGTCTCAGGGAGCAAAAGCAGGGG \\
HA-H1-345F & HA (H1) & $345-365$ & GGAACGTGTACCCAGGAGAT \\
HA-H1-680F & HA (H1) & $680-701$ & TCAAGCCGGAAATAGCAATAAG \\
HA-H1-1137F & HA (H1) & AGCCGACCTGAAGAGCACAC \\
HA-H1-714R & HA (H1) & CCTCACTTGGGTCTTATTGCTAT \\
HA-H1-1093R & HA (H1) & CATCCATCTACCATCCCTGTCC \\
HA-H1-1330R & $1072-1093$ & GCATTGTAAGTCCAAATGTCCA \\
A-uni-HA-1807R & HA (H1) & ATATCGTCTCGTATTAGTAGAAACAAGGGTGTTIT \\
A-uni-NA-1F & HA & TATTGGTCTCAGGGAGCAAAAGCAGGAGT \\
H1-NA-324F & NA & $1773-1807$ & GGTTCCAAGGGGGATGTGTTG \\
H1-NA-744F & NA (N1) & $1-29$ & TGGACAGGCCTCATACAAGATCT \\
H1-NA-645R & NA (N1) & $324-345$ & AGTGTCTGTATTATTCCGTGTA \\
H1-NA-1010F & NA (N1) & $744-766$ & CAGTATCGTCTAATGGAGCAAATGGA \\
H1-NA-1057R & NA (N1) & $622-645$ & CTATCCAAACACCATTGCCGTA \\
A-uni-NA-1442R & NA (N1) & ATATGGTCTCGTATTAGTAGAAACAAGGAGTTIIIT
\end{tabular}

\section{One-step multiplex real-time reverse transcription-} polymerase chain reaction (RT-PCR)

RT-PCR was carried out using the Agpath ID One-step RT-PCR system (Applied Biosystems, Foster City, CA, USA) [10]. Table 1 lists multiplex (A/B/IPC and H1/H3/ IPC) primer and Taq-Man probe sets. The $20-\mu \mathrm{L}$ reaction mixture contained $5 \mu \mathrm{L}$ of RNA template, $590 \mathrm{nM}$ primers, $140 \mathrm{nM}$ probe, $10 \mu \mathrm{L}$ of $2 \times$ reaction buffer, $0.8 \mu \mathrm{L}$ of enzyme mixture, and RNase-free water. RTPCR was performed on the ABI 7500Fast instrument (Applied Biosystems) with thermocycler conditions for reverse transcription $\left(50^{\circ} \mathrm{C}, 30 \mathrm{~min}\right)$, hot start DNA Taq polymerase activation $\left(95^{\circ} \mathrm{C}, 10 \mathrm{~min}\right)$, followed by $40 \mathrm{cy}$ cles of denaturation $\left(95^{\circ} \mathrm{C}, 15 \mathrm{~s}\right)$ and annealing/extension $\left(55^{\circ} \mathrm{C}, 30 \mathrm{~s}\right)$. Data acquisition and analysis of the real-time PCR assay were performed using SDS software Version 1.4 (Applied Biosystems).

\section{Virus isolation in MDCK cell lines}

Madin-Darby canine kidney (MDCK, American Type Culture Collection, Manassas, VA, USA) cells were seeded at $10^{5} / \mathrm{mL}$ in T25 flasks with Dulbecco's modified Eagle medium (Hyclone, Logan, UT, USA) containing $10 \%$ fetal bovine serum (Hyclone) and 1\% penicillinstreptomycin (Sigma, St. Louis, MO, USA) in a final volume of $5 \mathrm{~mL}$ and incubated at $37^{\circ} \mathrm{C}$ in a humidified atmosphere with $5 \% \mathrm{CO}_{2}$ for $48 \mathrm{~h}$. When the cells reached $90 \%$ confluence, the culture medium was discarded, and the cells were washed three times with warm phosphatebuffered saline. Then, $0.2 \mathrm{~mL}$ of clinical specimen was added into a flask to allow the inoculum to adsorb $\left(37^{\circ} \mathrm{C}, 60 \mathrm{~min}\right)$. Medium $(5 \mathrm{~mL})$ containing $2 \mu \mathrm{L} / \mathrm{mL}$ TPCK-trypsin was added to the flask. The culture was observed daily for cytopathic and morphological changes using an inverted light microscope. The culture supernatant was harvested when $75-100 \%$ of the infected cells showed cytopathic effect and stored at $-70{ }^{\circ} \mathrm{C}$ [11]. Finally, A/Korea/S0002/2019 and A/Korea/S0003/2019 $\mathrm{A}(\mathrm{H} 1 \mathrm{~N} 1) \mathrm{pdm} 09$ viruses were isolated.

\section{Hemagglutinin (HA) and neuraminidase (NA) sequencing} Viral RNA was extracted from oropharyngeal swab samples and their isolates using the QIAamp Viral RNA Mini Kit (Qiagen) according to the manufacturer's instructions. Reverse transcription was performed to obtain cDNA using the U12 primer, then the HA and NA genes were amplified with specific primers [12]. The PCR products were purified using the QIAquick ${ }^{\mathrm{Tm}}$ PCR Purification Kit (Qiagen) according to the manufacturer's instructions and subjected to direct sequencing using the Big Dye Terminator V.3.0 Cycle Sequencing Ready Reaction Kit (Applied Biosystems) together with primers for each PCR fragment (Table 2) on the ABI 3130xl Genetic Analyzer automatic sequencer (Applied Biosystems). The nucleotide sequences were edited, assembled, and aligned using MEGA X 10.1 software (https://www.megasoftware.net/). The complete HA

Table 3 A(H1N1)pdm09 virus detection in immunocompromised patients by real-time RT-PCR

\begin{tabular}{llllll}
\hline Patient & \multicolumn{5}{l}{ Genetic detection using real-time RT-PCR } \\
\cline { 2 - 6 } & IFV A & IFV B & A/H1 & A/H3 & IPC \\
\hline A & 26.1 & UD $^{*}$ & 25.4 & UD $^{*}$ & $26.3 / 26.2$ \\
B & 27.0 & UD $^{*}$ & 25.8 & UD $^{*}$ & $32.1 / 34.0$ \\
\hline
\end{tabular}

UD*: undetected 
- Vaccine virus

Reference virus

NAl-resistant virus

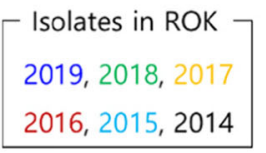

NA1 numbering

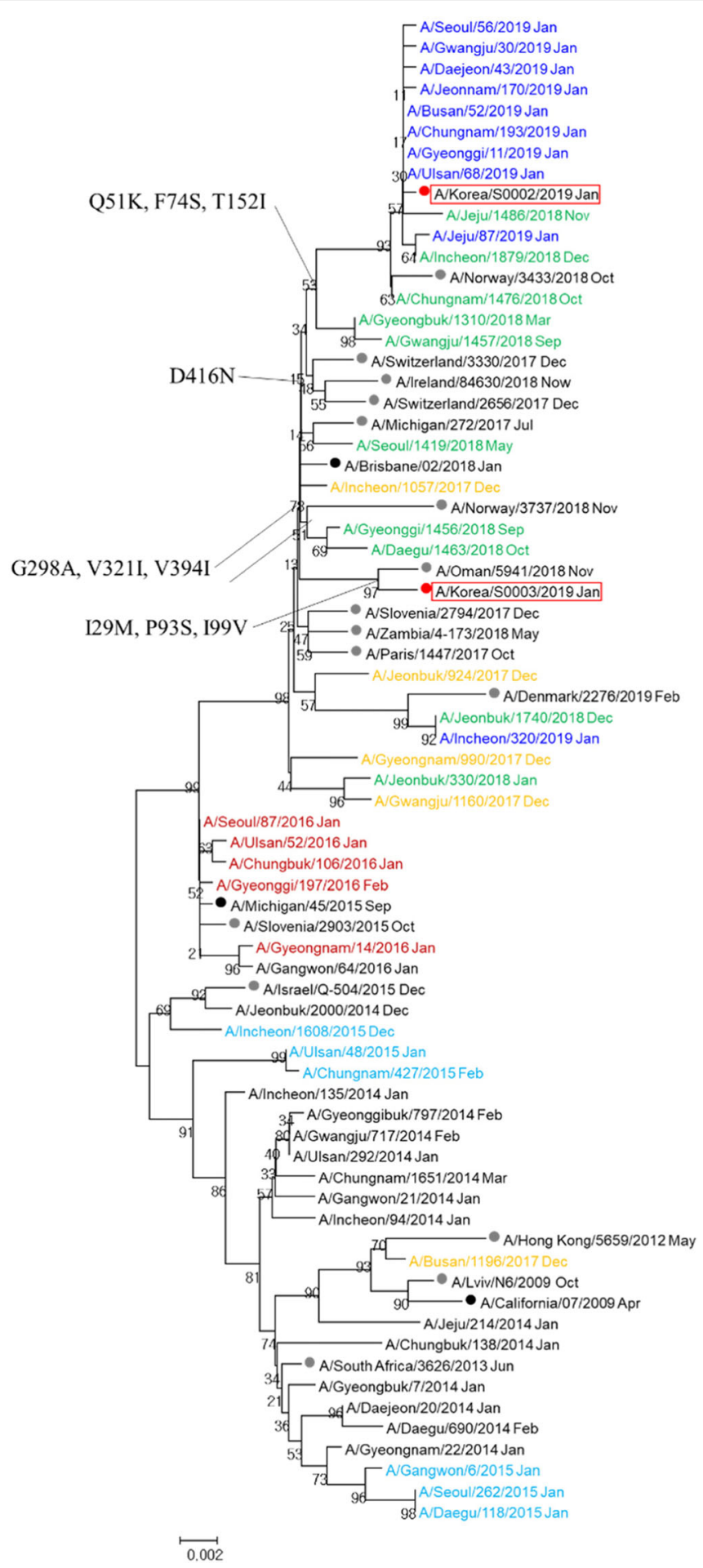

Fig. 1 Phylogenetic tree of neuraminidase (NA) gene of drug resistant A(H1N1)pdm09. The H275Y mutated viruses (A/Korea/S0002/2019 and A/ Korea/S0003/2019) were not identical in phylogenetic tree of NA. A/Korea/S0002/2019 harbored Q51K, F74S, T152I and D416N mutation and A Korea/S0003/2019 harbored I29M, P93S, 199V, G298A, V321I and V394I mutation compared to A/Brisbane/02/2018

(GISAID: EPI1602907 and EPI1602905) and NA (GISAID: EPI1602908 and EPI1602906) sequences were obtained from the $2 \mathrm{~A}(\mathrm{H} 1 \mathrm{~N} 1) \mathrm{pdm} 09$ viruses.

\section{Genetic characterization}

Genetic screening for drug resistance in the NA gene and mutational analysis of the HA and NA genes were 
conducted using Flusurver (https://flusurver.bii.a-star. edu.sg/), last updated on July 26, 2019. Phylogenies were reconstructed using the neighbor-joining method and bootstrapped 1000 times with MEGA X 10.1 using HAor NA-aligned DNA sequences of the A(H1N1)pdm09 reference vaccine [13] and other isolates from the Republic of Korea.

\section{NA inhibition assay}

A fluorescence-based neuraminidase inhibition assay was conducted using the NA-Fluor ${ }^{\mathrm{Tm}}$ Influenza Neuraminidase Assay Kit (Applied Biosystems), according to the manufacturer's instructions. The susceptibility of influenza viruses to NAI was characterized using oseltamivir, zanamivir, and peramivir at concentrations that inhibited the NA activity by $50 \%\left(\mathrm{IC}_{50}\right)$ as described previously [14]. As defined by the WHO, influenza A viruses with normal, reduced, and highly reduced NA activity inhibition exhibit a $<10$-fold, 10 - to 100-fold, and $\geq 100$-fold increase in $\mathrm{IC}_{50}$, respectively; the last are considered clinically resistant [15].

\section{Hemagglutination inhibition ( $\mathrm{HI})$ assay}

Assays were performed according to standard methods [16]. Four HA units $/ 25 \mu \mathrm{L}$ of $\mathrm{A}(\mathrm{H} 1 \mathrm{~N} 1) \mathrm{pdm} 09$ virus were tested using $0.5 \%$ suspensions of turkey red blood cells. $\mathrm{HI}$ titers were reciprocals of the highest dilutions of sera that inhibited hemagglutination. Post-infection ferret antisera against $18-19$ and $19-20$ vaccine viruses were treated with receptor-destroying enzyme (Denka Seiken, Tokyo, Japan).

\section{Results}

\section{$A(H 1 N 1) p d m 09$ detection and isolation in} immunocompromised patients

Influenza A virus was detected in oropharyngeal swab samples collected from patients with lymphoblastic leukemia (Patient A: female, 37 years old) and relapsed lymphoma (Patient B: female, 38 years old), with real-time RT-PCR Ct values of 28 and 29 , respectively. $\mathrm{A}(\mathrm{H} 1 \mathrm{~N} 1) \mathrm{pdm} 09$ viruses were identified by additional $\mathrm{H} 1$ subtype detection at respective Ct values of 28 and 29 (Table 3). Plaques were observed within $48 \mathrm{~h}$ following specimen inoculation in MDCK cells, with the harvested supernatant exhibiting an HA titer of 256. The isolates were named A/Korea/S0002/ 2019 and $\mathrm{A} /$ Korea/S0003/2019.

\section{Genetic characterization \\ NA genetic analysis for screening drug resistance, phylogeny, and variation}

The sequences of the NA gene from oropharyngeal swab samples and the isolated viruses from each patient were determined and were found to have no mutations resulting from adaptation to the cell culture conditions. The H275Y NA substitution (N1 numbering), associated with strong drug resistance, was observed in (GISAID: EPI1602908 and EPI1602906) of A(H1N1)pdm09 isolates from both immunocompromised patients. Other NA drug-resistance substitutions (V116A, I117V, Q136K, D151A, Y155H, R156K, D198V, I222V, R224K, Q226H, E227D, E277Q, R293K, N294S, E425G, and I436N) were not detected. The NA sequences of $\mathrm{A} /$ Korea/S0002/2019 and A/Korea/S0003/2019 most closely matched with those of A/Brisbane/02/2018 (98.5 and $98.3 \%$ amino-acid identity, respectively). The viruses could be distinguished in the phylogenetic tree (Fig. 1). A/Korea/S0002/2019 had six amino acid differences (T13I, Q51K, F74S, H275Y, D416N, and T452I) relative to A/Brisbane/02/2018 (Table 4), while A/Korea/S0003/ 2019 had eight (T13I, I29M, P93S, I99V, H275Y, G298A, V321I, and V394I). Table 4 shows the amino acid substitutions in NA compared with A/Brisbane/02/2018 and their reported effects.

\section{HA phylogeny and variation}

In the HA phylogenetic tree, two viruses belonged to clade 6B.1A, including A/Brisbane/02/2018 and a virus similar to a 2018-2019 season-isolated A(H1N1)pdm09 in the Republic of Korea. A/Korea/S0002/2019 and A/ Korea/S0003/2019 HA sequences best matched with those of A/Brisbane/02/2018 (98.6 and 98.9\% aminoacid identity, respectively). The two viruses fell into

Table 4 NA genetic mutations compared with A/Brisbane/02/2018 (N1 numbering)

\begin{tabular}{|c|c|c|c|c|c|c|c|c|c|c|c|c|c|}
\hline Virus & $\begin{array}{l}\text { Amino acid identity with A/ } \\
\text { Brisbane/02/2018 (\%) }\end{array}$ & $\mathrm{T} 13 \mid$ & 129M & Q51K & F74S & P935 $S^{a, b}$ & $199 \mathrm{~V}^{\mathrm{b}}$ & $\mathrm{H} 275 \mathrm{Y}^{\mathbf{c}}$ & $G 298 A^{a}$ & $\mathrm{~V} 3211^{\mathrm{a}}$ & $\left.V_{394}\right|^{b}$ & $\mathrm{D} 416 \mathrm{~N}^{\mathrm{a}, \mathrm{b}}$ & $T 452^{a, b, d}$ \\
\hline $\begin{array}{l}\text { A/Korea/ } \\
\text { S0003/2019 }\end{array}$ & 98.3 & $\circ$ & $\circ$ & & & $\circ$ & $\circ$ & $\circ$ & $\circ$ & $\circ$ & $\circ$ & & \\
\hline $\begin{array}{l}\text { A/Korea/ } \\
\text { S0002/2019 }\end{array}$ & 98.5 & $\circ$ & & ○ & $\circ$ & & & $\circ$ & & & & ० & $\circ$ \\
\hline Frequency (\%) & & 99.79 & 0.65 & 18.14 & 16.78 & 0.34 & 0.89 & 0.58 & 0.75 & 1.13 & 1.37 & 36.25 & 18.76 \\
\hline
\end{tabular}

o substitution of the amino acid indicated

${ }^{a}$ Binding small ligand

${ }^{b}$ viral oligomerization interfaces

cstrong drug resistance

dbinding host protein 
- Vaccine virus

- Reference virus

NAl-resistant virus

$\left[\begin{array}{c}\text { Isolates in ROK } \\ 2019,2018,2017 \\ 2016,2015,2014\end{array}\right]$

HA1 numbering

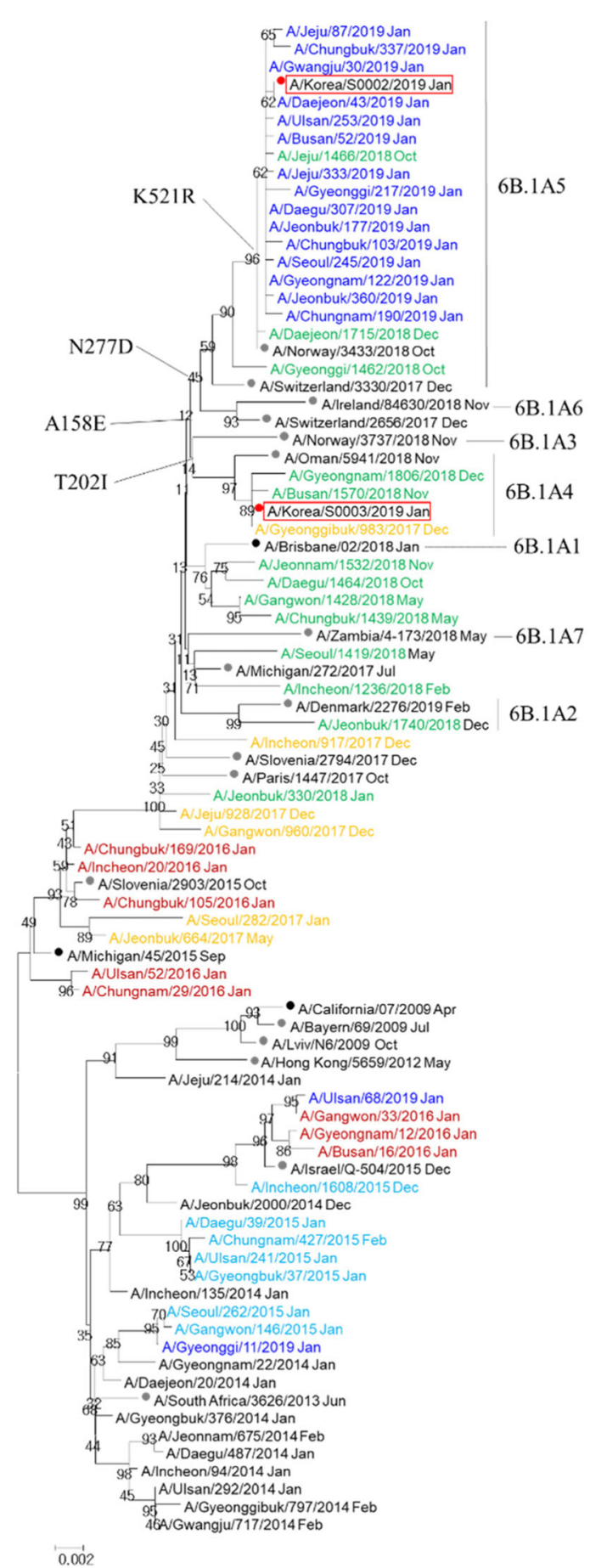

$6 \mathrm{~B} .1 \mathrm{~A}$

Fig. 2 Phylogenetic tree of hemagglutinin (HA) gene of drug resistant $A(H 1 N 1) p d m 09$. A/Korea/S0002/2019 virus belonged to 6B.1A5 harboring T2021, N277D and K521R mutations compared to A/Brisbane/02/2018 and clustered with isolated viruses in 2019year, Republic of Korea (ROK), whereas A/Korea/S0003/2019 virus belonged to 6B.1A4 harboring A158E mutation and clustered with isolated viruses in previous year

different subclades according to discrepancies at residues 158, 202, 277, and 521. A/Korea/S0002/2019 belonged to subclade 6B.1A5 and A/Korea/S0003/2019 to subclade 6B.1A4 (Fig. 2). Table 5 shows the amino-acid substitutions in the HA gene compared with A/Brisbane/02/2018 and their reported effects. 
Table 5 HA genetic variation compared with A/Brisbane/02/2018 (H1 numbering)

\begin{tabular}{|c|c|c|c|c|c|c|c|c|c|c|}
\hline Virus & $\begin{array}{l}\text { Amino acid identity with A/Brisbane/02/ } \\
2018(\%)\end{array}$ & $G 62 R^{a, b, c}$ & $\mathrm{~N} 146 \mathrm{D}^{\mathrm{a}, \mathrm{b}, \mathrm{c}}$ & $\begin{array}{l}\mathrm{A} 158 \mathrm{E} \\
\mathrm{a}, \mathrm{b}, \mathrm{C}\end{array}$ & $\begin{array}{l}\text { T2021 } \\
a, b, c\end{array}$ & $\begin{array}{l}\text { R240Q } \\
\underset{a, c, d}{ }\end{array}$ & $\mathrm{~N} 277 \mathrm{D}^{\mathrm{b}}$ & A299pa & V315 $\left.\right|^{a, b}$ & $\mathrm{~K} 521^{\mathrm{b}}$ \\
\hline $\begin{array}{l}\text { A/Korea/S0003/ } \\
2019\end{array}$ & 98.94 & 0 & $\circ$ & $\circ$ & & $\circ$ & & $\circ$ & $\circ$ & \\
\hline $\begin{array}{l}\text { A/Korea/S0002/ } \\
2019\end{array}$ & 98.59 & $\circ$ & $\circ$ & & $\circ$ & $\circ$ & $\circ$ & $\circ$ & $\circ$ & $\circ$ \\
\hline Frequency (\%) & & 84.19 & 17.76 & 0.97 & 19.77 & 99.87 & 29.46 & 84.85 & 85.38 & 3.08 \\
\hline
\end{tabular}

o substitution of the amino acid indicated

ainding small ligand

${ }^{b}$ viral oligomerization interfaces

cantibody recognition sites

dhost cell receptor binding

\section{NA inhibition assay}

A/Korea/S0003/2019 and A/Korea/S0002/2019 viruses exhibited significantly reduced inhibition by oseltamivir and peramivir with > $100 \mathrm{IC}_{50}$ fold-changes relative to drugsensitive virus, but were normally susceptible to zanamivir (Table 6). However, every isolate collected from the KINRESS in 2018-2019 was susceptible to all three drugs.

\section{Antigenic characterization}

The two viruses were well inhibited by antisera from ferrets immunized with A/Michigan/45/2015 and A/Brisbane/02/2018, which are northern-hemisphere influenza $\mathrm{A}(\mathrm{H} 1 \mathrm{~N} 1)$ pdm09 isolates collected in 2018-2019 and 2019-2020, respectively, with less than two-fold reduced HI titer relative to homologous virus (Table 7).

\section{Discussion}

The NAI-resistant $\mathrm{A}(\mathrm{H} 1 \mathrm{~N} 1)$ virus harboring the NA gene $\mathrm{H} 275 \mathrm{Y}$ variation was first identified in 2007, and was frequently identified worldwide in 2008-2009 [17]. However, since the $2009 \mathrm{~A}(\mathrm{H} 1 \mathrm{~N} 1)$ pdm09 pandemic, it occurred in $<1 \%$ of $\mathrm{A}(\mathrm{H} 1 \mathrm{~N} 1)$ pdm09, mainly reported in patients with impaired immune systems due to immunosuppressive therapies for conditions including cancer and organ transplants $[18,19]$. Notably, such immunocompromised patients, when infected with influenza virus, could shed virus over a prolonged period, likely causing increased transmission. Moreover, as they shed drug-resistant virus while maintaining transmissibility, these patients may constitute a source for spreading drug-resistant influenza in the community [18].

Although NAI-resistant virus has been rarely observed since 2000, the KCDC, through the KINRESS, identified oseltamivir and peramivir-resistant $\mathrm{A}(\mathrm{H} 1 \mathrm{~N} 1) \mathrm{pdm} 09$ viruses harboring the $\mathrm{H} 275 \mathrm{Y}$ NA variation in patients with acute lymphoblastic leukemia and relapsed lymphoma hospitalized in the same general hospital, with both exhibiting prolonged virus excretion. Although there was no history of the two patients occupying the same ward, we were concerned about potential NAI-resistant virus transmission. The phylogenetic analysis showed that the two isolated $\mathrm{A}(\mathrm{H} 1 \mathrm{~N} 1) \mathrm{pdm} 09$ viruses were genetically distinct. Moreover, there were no additional reports of similar viruses in that hospital. Furthermore, van der Vries et al. [20] demonstrated that $\mathrm{A}(\mathrm{H} 1 \mathrm{~N} 1)$ pdm09 virus-infected immunocompromised ferrets exhibited prolonged virus replication despite antiviral therapy, along with the $\mathrm{H} 275 \mathrm{Y}$ substitution observed in the virus population from day 8 onwards only in ferrets that received oseltamivir. These results suggest that the H275Y substitution emerges rapidly in immunocompromised hosts under continuous antiviral selective pressure.

Mutations suspected to represent antigenic drift in immunocompromised patients were more likely to be observed in NA than HA, albeit at a very low frequency (around 1\%). However, the NA mutations did not affect

Table 6 Neuraminidase inhibition assay for A(H1N1)pdm09 viruses isolated in immunocompromised patients

\begin{tabular}{|c|c|c|c|c|c|}
\hline \multirow[t]{2}{*}{ Virus } & \multirow[t]{2}{*}{ Type (Subtype) } & \multirow[t]{2}{*}{ Genotype } & \multicolumn{3}{|c|}{ NAl resistance (I $C_{50}$ fold change) } \\
\hline & & & Oseltamivir & Zanamivir & Peramivir \\
\hline A/Korea/S0003/2019 & $\mathrm{A}(\mathrm{H} 1 \mathrm{~N} 1) \mathrm{pdm} 09$ & Variant $(\mathrm{H} 275 \mathrm{Y})$ & $\begin{array}{l}\text { HRI } \\
179.33\end{array}$ & $\begin{array}{l}\mathrm{NI} \\
2.56\end{array}$ & $\begin{array}{l}\text { HRI } \\
117.74\end{array}$ \\
\hline A/Korea/S0002/2019 & & Variant $(\mathrm{H} 275 \mathrm{Y})$ & $\begin{array}{l}\text { HRI } \\
221.58\end{array}$ & $\begin{array}{l}\mathrm{Nl} \\
0.44\end{array}$ & $\begin{array}{l}\text { HRI } \\
168.48\end{array}$ \\
\hline \multirow[t]{3}{*}{ 2018-2019 isolates } & $\mathrm{A}(\mathrm{H} 1 \mathrm{~N} 1) \mathrm{pdm} 09$ & Wild & $0.1-1.2$ & $0.3-0.7$ & 0.1 \\
\hline & $\mathrm{A}(\mathrm{H} 3 \mathrm{~N} 2)$ & Wild & $0.1-0.2$ & $0.4-0.8$ & $0.2-0.3$ \\
\hline & B & Wild & 9-16 & $0.7-1.6$ & $0.3-0.4$ \\
\hline
\end{tabular}


Table 7 Hemagglutinin inhibition assay

\begin{tabular}{lll}
\hline Virus & \multicolumn{2}{l}{ Hemagglutination inhibition titer } \\
\cline { 2 - 3 } & Post-infection ferret antisera & A/Brisbane/02/2018 Egg \\
\cline { 2 - 3 } & A/Michigan/45/2015 Egg & 640 \\
\hline A/Korea/S0003/2019 MDCK & 640 & 640 \\
A/Korea/S0002/2019 MDCK & 320 & 640 \\
A/Michigan/45/2015 MDCK & 1280 & 1280 \\
A/Brisbane/02/2018 MDCK & 640 & \\
\hline
\end{tabular}

antigenic properties, besides drug resistance. Although the HA N158D substitution increases the binding affinity of $\mathrm{H} 5 \mathrm{~N} 1$ avian influenza virus and human receptor ( $\alpha 2-6$-linked sialoside) [21], the function of the A/ Korea/S0002/2019 HA A158E substitution functionality remains unknown (but it was not involved in antigenicity in this study). Alternatively, NA and HA had different mutation spectra in swine influenza viruses collected from April to June 2019 in the United States. The antigenic drift in immunocompromised patients may allow swine influenza virus insertion to occur without pig to human transmission, ultimately reducing the efficacy of influenza vaccine escape. Nevertheless, antisera from ferrets immunized with the influenza vaccine exhibited good inhibition of A/Korea/S0002/2019 and A/Korea/ S0003/2019 infection.

\section{Conclusions}

The NA H275Y substitution and some HA or NA substitutions in drug-resistant $\mathrm{A}(\mathrm{H} 1 \mathrm{~N} 1) \mathrm{pdm} 09$ viruses isolated from immunocompromised patients influence both antigenicity and NAI resistance. The viruses showed highly reduced inhibition, with over 100 -fold increases in the $\mathrm{IC}_{50}$ for oseltamivir and peramivir, but not zanamivir. Thus, zanamivir might be an option for immunocompromised patients when oseltamivir and peramivir are not effective. These findings also indicate the necessity of monitoring for NAI-resistant viruses in outpatients visiting clinics and in-patients, particularly for immunocompromised patients (e.g., with severe acute respiratory syndromes in general hospitals). Additionally, virus characterization can facilitate the risk assessment of NAI viruses.

\section{Abbreviations \\ KINRESS: Korea Influenza and Respiratory Viruses Surveillance System; SARI: Severe Acute Respiratory Infection; H: Histidine; Y: Tyrosine; NAls: Neuraminidase inhibitors; NA: Neuraminidase; HA: Hemagglutinin; MDCK: Madin-Darby canine kidney; GISAID: Global Initiative on Sharing All Influenza Data; $I_{50}$ : Half maximal inhibitory concentration}

\section{Acknowledgments}

We thank the national influenza surveillance participating institutes.

\section{Authors' contributions}

Conception and design: Chun Kang, Yoon-Seok Chung. Acquisition of data: Namjoo Lee, Mi-Seon Kim. Analysis and interpretation: Heui Man Kim, Yoon-
Seok Chung. Writing, review and revision of the manuscript: Heui Man Kim. Study supervision: Chun Kang, Yoon-Seok Chung. All authors read and approved the final manuscript.

\section{Funding}

This study was supported by intramural funding from Korea Centers for Disease Control and Prevention (4834-303).

\section{Availability of data and materials}

The data supporting the conclusions of this article are included within the article.

\section{Ethics approval and consent to participate}

All experimental procedures were approved by the institutional review boards of Korea Centers for Disease Control and Prevention (Ethics number: 2016-05-02-P-A)

\section{Consent for publication}

Not applicable.

\section{Competing interests}

The authors declare that they have no competing interests.

Received: 18 March 2020 Accepted: 30 June 2020

Published online: 06 July 2020

\section{References}

1. Cooper NJ, Sutton AJ, Abrams KR, Wailoo A, Turner D, Nicholson KG. Effectiveness of neuraminidase inhibitors in treatment and prevention of influenza a and B: systematic review and meta-analyses of randomized controlled trials. BMJ. 2003;326:1235.

2. McKimm-Breschkin JL. Influenza neuraminidase inhibitors: antiviral action and mechanisms of resistance. Influenza Other Respir Viruses. 2013;7:25-36.

3. Heo YA. Baloxavir: first global approval. Drugs. 2018:78:693-7.

4. Moasser $E$, Moasser $A$, Zaraket $H$. Incidence of antiviral drug resistance markers among human influenza a viruses in the eastern Mediterranean region, 2005-2016. Infect Genet Evol. 2019;67:60-6.

5. Redlberger-Fritz M, Aberle SW, Strassi R, Popow-Kraupp T. Rapid identification of neuraminidase inhibitor resistance mutations in seasonal influenza virus a (H1N1), a (H1N1) 2009, and a (H3N2) subtypes by melting point analysis. Eur J Clin Microbiol Infect Dis. 2012;31:1593-601.

6. World Health Organization. Summary table of neuraminidase amino acid substitutions associated with reduced inhibition by neuraminidase inhibitors (NAI). In: Laboratory methodologies for testing the antiviral susceptibility of influenza viruses: Neuraminidase inhibitors (NAI); 2018. https://www.who.int/ influenza/gisrs_laboratory/antiviral_susceptibility/nai_overview/en/. Accessed 26 Apr 2018

7. A*STAR Bioinformatics Institute. FluSurver. http://flusurver.bii.a-star.edu.sg/ Accessed 14 Mar 2016

8. Nguyen HT, Fry AM, Gubareva LV. Neuraminidase inhibitor resistance in influenza viruses and laboratory testing methods. Antivi Ther. 2012;17:15973.

9. Weinstock DM, Gubareva LV, Zuccotti G. Prolonged shedding of multidrugresistant influenza a virus in an immunocompromised patient. New Engl J Med. 2003;348:867-8.

10. Choi JH, Kim MS, Lee JY, Lee NJ, Kwon D, Kang MG, et al. Development and evaluation of multiplex real-time RT-PCR assays for seasonal, pandemic a/ 
H1 pdm09 and avian a/H5 influenza viruses detection. J Microbiol. 2013;51: 252-7.

11. Liu SS, Jiao XY, Wang S, Su WZ, Jiang LZ, Zhang $X$, et al. Susceptibility of influenza a (H1N1)/pdm2009, seasonal a (H3N2) and B viruses to Oseltamivir in Guangdong, China between 2009 and 2014. Sci Rep. 2017;7:8488.

12. Hoffmann E, Stech J, Guan Y, Webster RG, Perez DR. Universal primer set for the full-length amplification of all influenza a viruses. Arch Virol. 2001;146: 2275-89.

13. European Centre for Disease Prevention and Control. Influenza virus characterization, Summary Europe, May 2019. 2019. https://www.ecdc. europa.eu/en/seasonal-influenza/surveillance-and-disease-data/influenzavirus-characterisation. Accessed 10 June 2019.

14. Lackenby A, Besselaar TG, Daniels RS, Fry A, Gregory V, Gubareva LV, et al. Global update on the susceptibility of human influenza viruses to neuraminidase inhibitors and status of novel antivirals, 2016-2017. Antivir Res. 2018;157:38-46.

15. WHO GISRS Antiviral Susceptibility Expert Working Group. Summary of neuraminidase amino acid substitutions associated with reduced inhibition by neuraminidase inhibitors (NAl). Last updated 21 October 2016: World Health Organization; 2016

16. World Health Organization. Manual for the laboratory diagnosis and virological surveillance of influenza. 2011. ISBN 9789241518090

17. Okomo-Adhiambo M, Sleeman K, Ballenger K, Nguyen HT, Mishin VP, Sheu $\mathrm{TG}$, et al. Neuraminidase inhibitor susceptibility testing in human influenza viruses: a laboratory surveillance perspective. Viruses. 2010;2:2269-89.

18. Memoli MJ, Athota R, Reed S, Czajkowski L, Bristol T, Proudfoot K, et al. The natural history of influenza infection in the severely immunocompromised vs nonimmunocompromised hosts. Clin Infect Dis. 2013;58:214-24.

19. Trebbien R, Pedersen SS, Vorborg K, Franck KT, Fischer TK. Development of oseltamivir and zanamivir resistance in influenza a (H1N1) pdm09 virus, Denmark, 2014. Euro Surveill. 2017;22:30445.

20. van der Vries E, Stittelaar KJ, van Amerongen G, Veldhuis Kroeze EJ, de Waal $L$, Fraaij PL, et al. Prolonged influenza virus shedding and emergence of antiviral resistance in immunocompromised patients and ferrets. PLoS Pathog. 2013;9:e1003343

21. de Vries RP, Zhu X, McBride R, Rigter A, Hanson A, Zhong G, et al. Hemagglutinin receptor specificity and structural analyses of respiratory droplet-transmissible H5N1 viruses. J Virol. 2014;88:768-73.

\section{Publisher's Note}

Springer Nature remains neutral with regard to jurisdictional claims in published maps and institutional affiliations.

Ready to submit your research? Choose BMC and benefit from:

- fast, convenient online submission

- thorough peer review by experienced researchers in your field

- rapid publication on acceptance

- support for research data, including large and complex data types

- gold Open Access which fosters wider collaboration and increased citations

- maximum visibility for your research: over $100 \mathrm{M}$ website views per year

At BMC, research is always in progress.

Learn more biomedcentral.com/submissions 